\title{
Most Chinese Preschool Teachers Value Guided Play Over Free Play: Latent Profiles and Associated Predictors
}

\author{
Xunyi Lin ${ }^{1}$, Yutong Liao'2, Manli Xue ${ }^{1}$ and Yeshe Colliver ${ }^{3 *}$ \\ ${ }^{1}$ College of Education, Fujian Normal University, Fuzhou, China, ${ }^{2}$ College of Education, Nanchang Institute of Science \\ and Technology, Nanchang, China, ${ }^{3}$ School of Education, Macquarie University, Sydney, NSW, Australia
}

Longitudinal research suggests that optimal long-term outcomes are achieved when early childhood education and care (ECEC) balance free with guided play. A prerequisite for this achievement is that ECEC teachers value both equally. This study examines preschool teachers' play beliefs profile and explores its association with teachers' backgrounds (e.g., teaching experience, education level) in a sample of 674 Chinese teachers in Fujian, China. Participants completed an adapted form of the Parent Play Belief Scale, the Chinese Teacher Play Beliefs Scale (CTPBS), to report their beliefs

OPEN ACCESS

Edited by: Yvette Renee Harris, Miami University, United States

Reviewed by: Feyza Tantekin Erden, Middle East Technical University,

Turkey

Brenna Hassinger-Das, Pace University, United States

*Correspondence: Yeshe Colliver yeshe.colliver@mq.edu.au

Specialty section:

This article was submitted to Developmental Psychology, a section of the journal

Frontiers in Psychology

Received: 21 September 2021

Accepted: 28 October 2021

Published: 29 November 2021

Citation:

Lin X, Liao Y, Xue M and Colliver Y (2021) Most Chinese Preschool Teachers Value Guided Play Over

Free Play: Latent Profiles

and Associated Predictors.

Front. Psychol. 12:780367.

doi: 10.3389/fpsyg.2021.780367 regarding young children's play and early academics. Latent profile analysis (LPA) revealed $91 \%$ of teachers exhibited high Academics over Guided Play (AGP) and low Free Play and Socio-Emotional Skills Support (FPSSS), whereas only 9\% were high in both factors. Teachers with a decade or more teaching experience were more likely to belong to the high AGP and low FPSES profile. The findings indicate that the majority of Chinese ECEC teachers value guiding play to academic skills more than they do facilitating free play for socio-emotional skills. Professional development focused on balancing guided with free play may be necessary for the majority of Chinese ECEC teachers to catch up with the zeitgeist of contemporary international research and policy on intentional teaching in play.

Keywords: play beliefs, Chinese teachers' perspectives, early childhood education and care (ECEC), intra-cultural variation, latent profile analysis (LPA)

\section{INTRODUCTION}

Cross-cultural comparative studies have revealed preschool teachers from various backgrounds attribute different characteristics and significance to children's play (e.g., Wu and Rao, 2011; van der Aalsvoort et al., 2015). For example, the emphasis on teacher-directed academic training in traditional Chinese culture has been linked to the influence of Confucianism (Zhu and Zhang, 2008). Progressive educational concepts and practices including child-centered, play-based teaching and learning have been exported from European-heritage to many Eastern countries including China since the end of the twentieth century (Rao et al., 2010; Li and Wang, 2017). It has been shown that Chinese early childhood education and care (ECEC) teachers increasingly believe that play is extremely valuable ( $\mathrm{Li}$ and $\mathrm{Chen}, 2017$ ). These beliefs toward play not only influence the curricula and their pedagogical practices (Parker and Neuharth-Pritchett, 2006; Yin et al., 2021), but also children's early learning and development (Kansanen, 1991). 
Crucially, large longitudinal research has significantly shaped the zeitgeist of contemporary ECEC practice (Bennett, 2005; Fleer, 2010) by showing that ECEC services in which children initiate about half of their activities throughout the day lead to the best long-term outcomes (Sylva et al., 2004). Of the childinitiated activities (that is, of the "play" activities; Breathnach et al., 2017, p. 447), it was optimal for children's long-term achievement when "almost half" were guided by adults (Sylva et al., 2004, p. 36). This means a 1:1 ratio of guided and free play is likely to be ideal (Sylva et al., 2004; Siraj-Blatchford, 2009). As a first step toward ECEC teachers reaching this ideal practice, their play beliefs must value this 1:1 ratio; as practice can only attain this balance once teachers have this intention and then gain the requisite experience in how to enact the intention (Parker and Neuharth-Pritchett, 2006; Yin et al., 2021). Yet reviews of ECEC teachers' beliefs reveal considerable variation internationally (Bubikova-Moan et al., 2019). Few studies (e.g., Izumi-Taylor et al., 2010; Rengel, 2013; Peterson et al., 2018) have quantified ECEC teachers' play beliefs using a validated scale, or sought to examine intra-cultural variation of beliefs that would help policy makers target interventions for changing teachers' beliefs, and, ultimately practices to improve the quality of ECEC (Bubikova-Moan et al., 2019, p. 779). In this endeavor, from a bioecological approach (Bronfenbrenner and Morris, 2006), it is also necessary to consider the influence of socio-cultural contexts (Hedegaard, 2009) and teachers' personal experiences (Ivrendi, 2017) on play beliefs. In particular, the broader cultural context must be understood if research endeavors to unearth intra-cultural differences in play beliefs (Haight et al., 1997). Despite powerful arguments about the significance of play for children's learning and development (e.g., Weisberg et al., 2013a) - and play being the basis of ECEC curriculum across the developed (Organization for Economic Cooperation and Development [OECD], 2017) and, increasingly, the developing world (Gupta, 2011; Li and Wang, 2017)—quantifying the extent to which teachers' education might influence their beliefs about play is an important first step in improving the quality of ECEC teacher education, and therefore young children's experiences in this crucial life stage (McCoy et al., 2017). Given that teacherguided play may be associated more with academic skills than is free play (which may be more associated with socio-emotional than academic skills) (Zosh et al., 2018), understanding whether ECEC teachers' play beliefs mirror the 1:1 ratio of free to guided play that is indicated to be optimal for child outcomes (Sylva et al., 2004; Siraj-Blatchford, 2009) is a vital first step in raising the effectiveness of ECEC (Ulferts et al., 2019). This study, therefore, sought to quantify Chinese ECEC teachers' play beliefs using a psychometrically sound measurement tool, the Chinese Teacher Play Beliefs Scale (CTPBS), and examine their relations to background variables such as education and experience levels.

\section{Play Beliefs of Early Childhood Education and Care Teachers}

Play is undoubtedly an essential daily activity of early childhood and theoretically impacts children's social, emotional, and cognitive development (e.g., Sylva et al., 2004;
Weisberg et al., 2013a; Zosh et al., 2018). Yet what teachers believe about play are thought to impact if and how they implement it within their pedagogy (Pyle and Danniels, 2017; Avornyo and Baker, 2018), and therefore whether it will assist in the quality of ECEC provision (Wen et al., 2011). Play beliefs are defined broadly as tacit, often unconsciously held assumptions about play and its relation to children's development (Haight et al., 1997; Fogle and Mendez, 2006). In extant studies, play beliefs are synonymous with values, conceptions, perceptions, perspectives, images, views, thoughts, judgments toward children's play (Pajares, 1992; Fives and Buehl, 2012; Baustad et al., 2018; Nilsen, 2021). Adults' beliefs contribute to positive or negative judgments about the significance of play (Fogle and Mendez, 2006). In particular, ECEC teachers' perspectives on play are important for the enactment of the most dominant type of ECEC approaches: play-based curricula (Avornyo and Baker, 2018). Acting as a contextual "filter" (Clark and Peterson, 1986), teachers' beliefs to some extent affect when teachers interpret, screen their classroom practices, and adapt the subsequent ones (Wen et al., 2011). Teachers' beliefs toward play and learning influence the curricula and their pedagogical practices, as well as children's early learning and development (Kansanen, 1991). Their beliefs are particularly important if ECEC is to have the life-long impact indicated by longitudinal research (e.g., McCoy et al., 2017), as teachers can only implement a balance of guided and free play if their values support this (Parker and Neuharth-Pritchett, 2006; Wen et al., 2011; Yin et al., 2021).

In a study by Hyvonen (2011), teachers' play beliefs were comprised of teachers' views on the effects of play on early childhood education, preference for the specific kinds of play, both of which determine how teachers arrange play activities. In most previous studies, the roles of teachers are varied by how teachers interact with children for better development in play activities. Some theorists argued that teacher participation may interfere with child play (e.g., Isaacs, 1929), and decades of teacher education and training have reinforced the idea that teacher involvement will only impair the maximal value of play for learning (Enz and Christie, 1993; Pyle and Danniels, 2017). Asian ECEC teachers have traditionally valued play less than their European-heritage counterparts (Bubikova-Moan et al., 2019), with beliefs in some countries (e.g., China) seeing play and learning as completely incompatible, meaning many activitiesincluding play-are adult-guided (Wu et al., 2018). Chinese ECEC curriculum has succumbed to the influence of Western education since it began "opening up" to globalization, both in policy and practice, since the 1980s (Zhu and Zhang, 2008, p. 174), most palpably since the 1989 "Kindergarten Work Regulations and Procedures" (p. 174). This policy emphasized the value of child-initiated activity and its integration with group and other activities (Qi and Melhuish, 2017). By the 1990s, the Reggio Emilia Approach (Edwards et al., 2011), The Zone of Proximal Development (Vygotsky, 1978) and the Project Approach (Helm and Katz, 2011) - each of which acknowledge the importance of child-initiated play-were all recognized in Chinese ECEC policy (Qi and Melhuish, 2017). Such national changes sit within an international context of empirical (Siraj-Blatchford, 2009; 
Weisberg et al., 2013b) and policy (Bennett, 2005; Rogers, 2013) trends toward a more active teacher role in children's play, which often calls for greater incorporation of academic content within children's learning activities. However, these rapid reforms were challenging for Chinese teachers (Zhu and Zhang, 2008, 2018). As noted in the famous "Preschool in Three Cultures" research, the reforms' success "depends on teachers' understanding of how and why to teach children in the ways the Guidelines suggest" (Tobin et al., 2009, p. 85). The views of parents, who may not agree with such child-centered approaches to early learning (Zhu and Zhang, 2008; Fung and Cheng, 2012), are likely to also contribute to Chinese ECEC teachers' current beliefs.

Other than differing beliefs about how much they value academic skills (e.g., literacy, numeracy) and child-initiated play, it is likely there is variation in beliefs how much teachers should involve themselves in children's play, as many scholars suggest this would abilities and promote their cognitive, social, and language development (Smilansky and Shefatya, 1990; Enz and Christie, 1993; Weisberg et al., 2013b; Pyle et al., 2021). Various authors identify specific roles ECEC teachers should move between when involved in play such as stage manager, play leader, director, co-player, and uninvolved coplayer (Enz and Christie, 1993; van Hoorn et al., 2014), model, mediator, allower, and afforder (Hyvonen, 2011). Indeed, the roles can be considered within the discourse of play regulation and support (Rengel, 2013), but do imply greater value on adult-determined content (e.g., academics) than a purely childinitiated approach. This might suggest that Chinese ECEC teachers have shifted from a teacher-directed curriculum to a child-centered one, only to be shifted more toward a view which values play and academics equally. Research has yet to confirm if this is so.

Previous studies have elaborated powerful arguments for the importance of play in children's education and identified variability in roles that ECEC teachers take in child play (Fisher et al., 2013; Weisberg et al., 2013b; Zosh et al., 2018). A vital first step in ensuring teachers take the most educationally valuable role in play is to determine the beliefs underpinning their practices. Given the culturally situated nature of these beliefs (Bronfenbrenner and Morris, 2006), a key piece in this first step is understanding the cultural beliefs of the most populous country in the world. China has received profound influence from Confucian heritage culture $(\mathrm{CHC})$, which values academic training in early childhood and highlights traditional teaching approach on children's development (Zhu and Zhang, 2008). In this cultural context, Chinese teachers may be regarded as an educational authority whose direction has long been widely encouraged, meaning the value of childinitiated, play-based activity has been overlooked (Li, 2012). Coupled with the lack of "faith" that many parents have in play, it is likely that there is some diversity in teachers' beliefs, as has been found in qualitative work in Chinese heritage (e.g., Fung and Cheng, 2012, p. 24) and European heritage contexts (e.g., Pyle and Danniels, 2017; Colliver, 2019). However, limited studies have examined the diversity in Chinese ECEC teachers' beliefs toward children's play. This study, therefore, aims to explore the variation in Chinese ECEC teachers' play beliefs.

\section{Person-Centered Study of Play Beliefs Within a Cultural-Historical Framework}

To examine the intra- cultural variation of Chinese ECE teachers' beliefs, we situated the study within a cultural-historical theory methodological framework, which aims to provide a "holistic" view of the phenomenon studied (Chaiklin, 2012, p. 209). For Rogoff (2003) "the interpersonal, personal, and culturalinstitutional aspects of the event constitute the activity... [n]o aspect exists or can be studied in isolation from the others" (p. 58). For the purposes of the current research questions, this approach is about seeing teachers' beliefs not as isolated from their context, but rather informing and informed by the larger societal, cultural, historical spheres, as well as the sub-cultures of each ECE setting (or preschool), the children attending, and their families (Bronfenbrenner and Morris, 2006). To do so, cultural-historical research examines activity and motive in one sphere as its units of analysis, maintaining the others "in the background" (Matusov, 2007, p. 324). Vygotsky, the grandfather of cultural-historical theory, saw this process as akin to studying the molecules within a drop of water to make inferences about the ocean; a "form of analysis (fundamental to) development of theories of thinking ...relies on the partitioning of the complex whole into units... those units in which the characteristics of the whole are present" (Vygotsky, 2004, p. 37). To Rogoff's (1995) three main planes of analysis-the individual, interpersonal, and cultural-institutional-Hedegaard (2008, p. 46) added the societal as a broader plane again. For the purposes of investigating intra-cultural variation in teachers' beliefs, it is appropriate to examine teachers' beliefs at the "institutional" level, as the beliefs are tied to the ECEC institution as their workplace (Colliver, 2019). In keeping with the focus on beliefs, it is possible to focus on participants' values within a cultural-historical approach, as they represent motives at the institutional level (Hedegaard, 2009), and motives are the key unit of analysis in cultural-historical research (Fleer, 2008). Values are often considered to be part of teachers' play beliefs (Nilsen, 2021).

Akin to these four levels of analysis, psychometric research can be conducted using variable-centered, person-centered, and person-specific approaches (Howard and Hoffman, 2018). Just as an institutional-level analysis will examine variation within a subcultural group of society (e.g., Chinese ECE teachers), despite its misleading name, a person-centered approach will determine if subgroups exist within a given population (Howard and Hoffman, 2018). This approach contrasts societal-level psychometric research, which most often uses variable-centered approaches to examine homogeneous groups of observations based on the combination of some independent variables (Bubikova-Moan et al., 2019). Variable-centered approaches may also examine the relationship of variables with play-learning beliefs (Mooi and Sarstedt, 2011; Avornyo and Baker, 2018). Notwithstanding, variable-centered analyses tend to ignore the intra-population variability, for they assume that associations are 
similar across all the participants (Howard and Hoffman, 2018). For example, Avornyo and Baker (2018) investigated Ghanaian early years stakeholders' play beliefs along the single dimension (i.e., the role of play in children's learning), roughly categorizing their play beliefs according to levels of education, and examined whether their education status could predict play-learning beliefs individually. However, it was noted that components of teachers' beliefs systems are often not isomorphic, and thus there exists the potential for belief variables to combine in novel ways that shape outcomes. Finally, person-specific approaches are used to examine relationships between variables at the individual level, and are inappropriately fine-grained for research on Chinese ECEC teachers' beliefs.

In contrast with studying ECEC teachers' play beliefs in isolation, person-centered approaches allow unique arrangements of play beliefs to be examined in association with their predictors or outcomes. Unlike variable-orientated procedures, the person-centered methodology can look at multiple ideas of addressing a specific issue, and better analyze multidimensional and correlated data (Bámaca-Colbert and Gayles, 2010). ECEC teachers with different cultural backgrounds emphasize different characteristics and significance of children's play (Sandberg and Samuelsson, 2003; Wu and Rao, 2011; van der Aalsvoort et al., 2015). In addition to culture, childhood experience is also considered key to beliefs and perceptions that are associated with adult beliefs and behavior (Thompson et al., 2008). Prior studies have reported variability in roles that teachers enact in children's play, as well as fluctuations in the role types (Johnson et al., 1999, p. 201; Pyle and Danniels, 2017). A more nuanced understanding could be garnered about the types of play beliefs among sub-populations of individuals identified based on within-group similarities and between-group differences in associations among variables. Person-centered approaches to analysis are well positioned to provide such an understanding (Howard and Hoffman, 2018).

To overcome apparent disadvantages of variable-centered analysis ( $\mathrm{Li}$ and Chen, 2017; Yang and Li, 2018; Lin et al., 2020), this study applied a person-centered approach via latent profile analysis (LPA) to explore the variation in ECEC teachers' play beliefs.

\section{Play Beliefs of Early Childhood Education and Care Teachers With Different Backgrounds}

Because the ECEC teacher holds a (if not the most) crucial role in the early education system, it is paramount that any investigation of their personal conceptualization and acceptance of the role is holistic (Edwards et al., 2011). Thus, concerning teachers' play beliefs, it is necessary to consider the influence of personal characteristics and socio-cultural contexts, from individual to society. Ivrendi's (2017) study showed that experienced teachers were busy with tasks unrelated to children's play more often than less experienced teachers. In addition, cross-culturally comparative studies have indicated that ECEC teachers with different cultural backgrounds emphasize different characteristics and significance of children's play (Izumi-Taylor et al., 2010; van der Aalsvoort et al., 2015). For example, none of the Japanese ECEC teachers in Izumi-Taylor et al. (2010) linked play to academic learning but teachers in the United Kingdom, United States, Germany, and Sweden did. Such differences across contexts might stem from variations in traditional cultural conceptions of how children develop (Avornyo and Baker, 2018). It is noted that, apart from differences, there exist some similarities in perceptions on play beliefs among early childhood educators from different backgrounds. Since progressive educational ideas and practices have been imported from European-heritage countries to other countries including China, more Chinese education authorities and parents have increasingly believed that play is a valuable medium for children's learning and development (Jiang and Han, 2016; Li and Chen, 2017).

Research focused on cross-cultural variation in ECEC teachers' beliefs on children's play has detracted from examination of intra-cultural variation in extant studies (Izumi-Taylor et al., 2010; Rengel, 2013; Peterson et al., 2018). For this reason, the current study draws on a person-centered approach to focus on the diversity in ECEC teachers' beliefs toward children's play in China and examine its relations to their backgrounds.

\section{The Current Study}

Acknowledging the diversity and complexity of prior investigations of ECEC teachers' play beliefs, the current study uses a person-centered approach via LPA to identify various profiles of individuals based on their play beliefs. Theoretically, we intend to contribute to the field through empirical evidence and substantiating the person-centered approach in play belief research. Researchers can acquire a more parsimonious but nuanced understanding of the play beliefs of different backgrounds. Practically, it informs early education authorities and practitioners of a convenient way to identify patterns of teachers' play beliefs and provide them with differentiated support.

Overall, the present study aims to: (a) identify patterns of ECEC teachers' play beliefs; (b) examine how these patterns are related to teachers' backgrounds; The following research questions guided this investigation:

(1) What group profiles of play beliefs would emerge from Chinese ECEC teachers?

(2) How are these profiles associated with teachers' background variables?

\section{MATERIALS AND METHODS}

\section{Participants}

This study was conducted in Fuzhou, the capital city of Fujian province, located in southeast China. Participants were informed that they could withdraw participation anytime and informed consent was given at the start of the survey. A total of 674 ECEC teachers were recruited from a variety of kindergartens, in both urban and rural areas to ensure sample diversity. As shown in Table 1, 172 teachers (25.5\%) had more than 10 years of teaching experience. The majority (65.4\%) of the teachers had 
TABLE 1 | Participant characteristics $(N=674)$.

\begin{tabular}{lc}
\hline Demographic characteristics & Frequency (\%) \\
\hline Education level & \\
High school and below & $89(13.2)$ \\
Associated degree & $352(52.2)$ \\
Bachelor degree and above & $233(34.6)$ \\
Teaching qualification & \\
Yes & $339(50.3)$ \\
No & $335(49.7)$ \\
Degree education major & \\
Preschool education & $607(90.1)$ \\
Others & $67(9.9)$ \\
Years teaching experience & \\
0-3 Years & $250(37.1)$ \\
$4-9$ Years & $252(37.4)$ \\
10 Years and above & $172(25.5)$ \\
\hline
\end{tabular}

an associated or lower degree and $34.6 \%$ of the teachers had a bachelor or above degree. Almost all (90.1\%) teachers specialized in preschool education. Around half (49.7\%) had no teaching qualification.

\section{Measures}

\section{Demographic Questionnaire}

In the questionnaire format, teachers reported their years teaching experience, education major, education level, and teaching qualification. Teachers were also required to provide basic information about their kindergartens, such as the location (urban or rural) and type (public or private).

\section{Chinese Teacher Play Beliefs Scale}

The CTPBS was developed and validated to assess Chinese ECEC teachers' beliefs toward young children's play and learning. Existing scales were mostly designed for parents and had not been adapted for ECEC teachers in China. In this study, we adapted the current parental play belief scale which used play vs. academics value dimension (e.g., Fogle and Mendez, 2006; Lin and Li, 2018), to include a child- vs. adult-guided play dimension, consistent with the international trends toward greater guidance of play by adults (Bennett, 2005; Colliver, 2019) and evidence that a balance between guided and free play is likely to be optimal for children's long-term achievement outcomes (Sylva et al., 2004; Siraj-Blatchford, 2009). Scale development processes resulted in a 13-item CTPBS scale (Watson et al., 1988). These included item assessment by experts in child development and play to confirm the scale's content validity, and crosscultural adaptation considerations for use with self-report data, including translating the English version to Mandarin, then back-translating these Mandarin versions to English again by a translator who was blinded to the original English version (Beaton et al., 2000; see Table 2). The factor structure of the scale was explored through principal component analyses with an Orthogonal (varimax) rotation method. Some principal criteria were used as a guide: (1) each retained factor has an eigenvalue larger than one; (2) the factor solutions explain
TABLE 2 | Structure and loadings of CTPBS for principal component analysis with varimax/promax rotation.

Scale item/version translated back from mandarin

Factor 1 Factor 2

Academics over guided play (AGP) (alpha $=0.86$ )

Q2. Child-initiated free play does not help children to learn

0.631 $-0.05$ academic skills like counting or recognizing letters/Free play initiated by children does not help them learn academic skills like counting or word recognition

Q6. It would be more beneficial to read to children than to join in on their play/Reading to children is more beneficial than participating in his/her play.

Q10. My child will get more out of play if I join in/Children will get more out of free play if I join in the play.

Q11. It is more important for children to have good

0.713 0.014 academic skills than to play well with others/lt is more important for children to have good academic skills than to play well with others.

Q12. Free playtime is not an everyday high priority in my class/Free playtime is not a priority for me every day in my class/kindergarten.

Q17. I do not think children learn important skills through play without adult guidance/l do not think children can learn important skills thorough play without adult guidance.

Q23. I should structure and guide about half of children's play/Half of the children's play should be structured and directed by me.

Q24. Play is best when adults structure it, to maximize learning/Play structured by adults is best for children to maximize learning.

\section{Free Play and Socio-Emotional Skills Support (FPSSS)}

(alpha $=0.84$ )

\begin{tabular}{lcc}
\hline Q4. I have a lot of fun with children when we play together/l & -0.054 & $\mathbf{0 . 6 4 7}$ \\
have a lot of fun with children when we play together. & & \\
$\begin{array}{l}\text { Q5. Free play can improve children's language and } \\
\text { communication abilities/Free play can improve children's }\end{array}$ & -0.054 & $\mathbf{0 . 6 9 1}$ \\
language and communication skills. & \\
$\begin{array}{l}\text { Q15. Free play can help children to learn to express his or } \\
\text { her feelings/Free play can help children learn to express }\end{array}$ & 0.09 & $\mathbf{0 . 7 7 5}$ \\
his/her feelings. & \\
$\begin{array}{l}\text { Q20. Through free play, children develop new skills and } \\
\text { abilities/Children can develop new skills and abilities }\end{array}$ & -0.02 & $\mathbf{0 . 8 7 4}$ \\
through free play. & & \\
Q21. Children gain social skills during free play/Children & -0.062 & $\mathbf{0 . 8 6 1}$ \\
learn social skills through free play. & &
\end{tabular}

Note: Salient Factor Loadings are bolded.

substantial proportion of the total variance with each factor accounting for more than $10 \%$ of the total variance; (3) item communality values were 0.40 or greater; (4) the item should have no cross-loadings among factors (5) each factor has at least three items and (6) factors demonstrate meaningfulness and interpretability in the content of their items. A twofactor model was selected for its best meeting to all criteria described above (see Table 2). CTPBS could be summarized by two factors, accounting for $55.86 \%$ of the total variance (32 and 23\%, respectively). As shown in Figure 1, a confirmatory factor analysis (using maximum likelihood extraction) for the two-factor model indicated that the model fit was satisfactory 

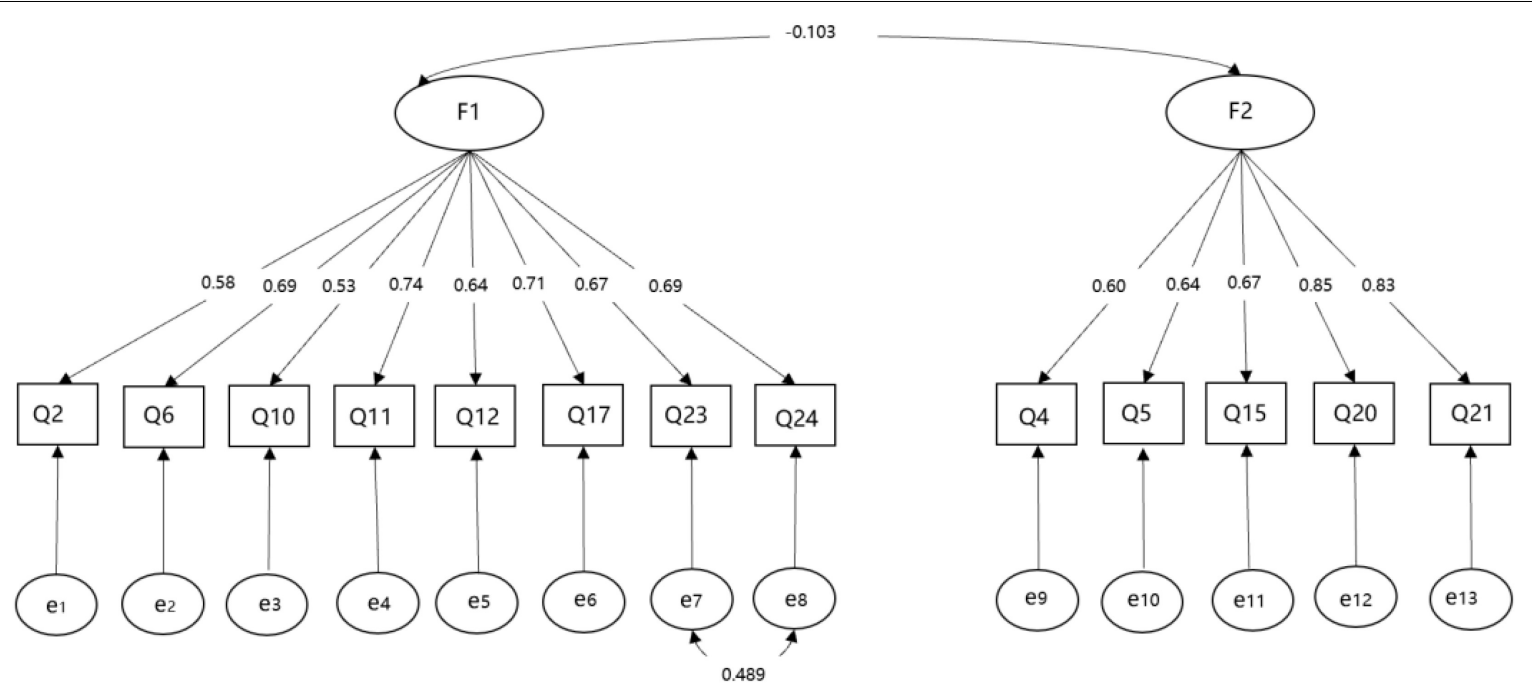

FIGURE 1 | Confirmatory factor analysis of ECEC teacher play beliefs.

$\left(\chi^{2}=246.376, D F=63, P=0.000, \mathrm{CFI}=0.947, \mathrm{TLI}=0.935\right.$, RMSEA $=0.076$, SRMR $=0.053)$.

In the CTPBS, teachers are required to complete a 5-point Likert scale ( $1=$ extremely disagree to $5=$ extremely agree) to evaluate their beliefs regarding young children's play and learning. The academic focus subscale included eight items that highlight the acquisition of knowledge and skills rather than free play for young children. For example, "Free play initiated by young children does not help them learn intellectual skills like counting or word recognition." The play support subscale contained 5 items that reflect an attention to the importance of child-free play, such as "Free play can improve children's language and communication skills." Cronbach's alpha coefficient was 0.79 for the CTPBS scale. For the two subscales, Cronbach's alphas coefficients were 0.86 and 0.84 , respectively.

\section{Theoretical Framework and Statistical Analyses}

The cultural influences nature on teachers' beliefs makes culturalhistorical theoretical framework most appropriate for the current investigative focus (Haight et al., 1997; Hedegaard, 2008). Within the tiered structure of influences of activity (societal, institutional, interpersonal and individual levels; Rogoff, 1995; Hedegaard, 2008), the institutionally nested nature of Chinese ECEC teachers' beliefs determined our institutional-level focus on values and beliefs, as discussed earlier. This level of analysis fits with the person-centered approach described within Howard and Hoffman's (2018) three levels of approach to psychological research, which, it is argued, should be chosen for its fit with the research question(s).

In the present study, LPA was used to discover diverse patterns of teachers' play beliefs. As a person-centered statistical approach, LPA allows researchers to find previously unnoticed subgroups among varied populations (Vermunt and Magidson, 2002; Vermunt, 2010). In comparison to traditional cluster analysis,
LPA uses rigorous model-fit indices to determine the number and character of the profiles, resulting in higher sensitivity to latent taxonomy detection (Cleland et al., 2000). To get the proper latent profile solution, we employed the following commonly used model-fit indices (Morin et al., 2011; Foti et al., 2012): The Akaike Information Criterion (AIC), Bayesian Information Criterion (BIC), and sample-size adjusted BIC (SSA-BIC), which should be smaller than those of other profiles; the Entropy value should be higher; the Vuong-Lo-Mendell-Rubin likelihood ratio statistics (VLMR) value and Bootstrap Likelihood Ratio Test (BLRT) value should be significant $(p<0.05)$. In addition to the above fitting indices, the solution of the model should also consider the theoretical limitations.

First, the mean scores of the two CTPBS subscales "Academics over Guided Play" (AGP) and "Free Play and Socio-Emotional Skills Support" (FPSSS) were employed as indicators to identify the latent profiles of teachers' play beliefs. Next, a series of LPA models were conducted in Mplus Version 8.0 using the full information maximum likelihood (FIML) as the estimation method (Muthén and Muthén, 1998-2010). Then, teachers' background information variables were used as predictors of the latent profile variable. Logistic regression was conducted in Mplus Version 8.0 with the indicators of years teaching experience, education major, education level, and teaching qualification to evaluate how these factors were associated with the Chinese ECEC teachers' play beliefs patterns.

\section{RESULTS}

The means, standard deviations and intercorrelations of variables are presented in Table 3. Play Support was positively related to teachers' education level $(r=0.192, p<0.001)$, years teaching experience $(r=0.138, p<0.001)$, and teaching qualification $(r=0.110, p<0.01)$. Academic Focus was positively related to teachers' education major $(r=0.109, p<0.01)$, whereas 
TABLE 3 | Means, standard deviations and intercorrelations of variables in this study.

\begin{tabular}{|c|c|c|c|c|c|c|}
\hline & $M(S D)$ & 1 & 2 & 3 & 4 & 5 \\
\hline $\begin{array}{l}\text { 1. Education } \\
\text { level }\end{array}$ & & 1 & & & & \\
\hline $\begin{array}{l}\text { 2. Teaching } \\
\text { qualification }\end{array}$ & & $0.542^{\star \star \star}$ & 1 & & & \\
\hline $\begin{array}{l}\text { 3. Degree } \\
\text { education } \\
\text { major }\end{array}$ & & $-0.229^{\star \star \star}$ & $-0.161^{\star \star \star}$ & 1 & & \\
\hline $\begin{array}{l}\text { 4. Years } \\
\text { teaching } \\
\text { experience }\end{array}$ & & $0.135^{\star \star \star}$ & $0.119^{\star \star}$ & $-0.103^{\star \star}$ & 1 & \\
\hline 5. AGP & $4.53(0.84)$ & $0.192^{\star \star \star}$ & $0.110^{\star \star}$ & -0.075 & $0.138^{\star \star \star}$ & 1 \\
\hline 6. FPSSS & $2.61(0.49)$ & $-0.194^{\star \star \star}$ & $-0.185^{\star \star \star}$ & $0.109^{\star \star}$ & $-0.151^{\star \star \star}$ & $-0.083^{*}$ \\
\hline
\end{tabular}

TABLE 4 | Latent profile analysis for Teacher's play beliefs.

\begin{tabular}{lccccc}
\hline & $\mathbf{1}$ & $\mathbf{2}$ & $\mathbf{3}$ & $\mathbf{4}$ & $\mathbf{5}$ \\
\hline AIC & 2636.310 & $\mathbf{2 5 2 8 . 2 1 6}$ & 2470.826 & 2270.953 & 2276.953 \\
BIC & 2654.363 & $\mathbf{2 5 5 9 . 8 0 9}$ & 2452.958 & 2329.625 & 2349.164 \\
Sample-size & 2641.663 & $\mathbf{2 5 3 7 . 5 8 3}$ & 2421.208 & 2288.348 & 2298.363 \\
adjusted BIC & & & & & \\
Entropy & & $\mathbf{0 . 9 0 0}$ & 0.790 & 0.886 & 0.876 \\
VLMR p-value & & $\mathbf{0 . 0 0 0 0}$ & 0.5118 & 0.6768 & 0.7448 \\
BLRT p-value & & $\mathbf{0 . 0 0 0 0}$ & 0.0000 & 0.0000 & 1.0000 \\
\%Profile1 & $100 \%$ & $\mathbf{9 1 . 1} \%$ & $27.0 \%$ & $3.1 \%$ & $3.1 \%$ \\
\%Profile2 & & $\mathbf{9 . 0 \%}$ & $66.2 \%$ & $55.2 \%$ & $55.2 \%$ \\
\%Profile3 & & & $6.8 \%$ & $6.7 \%$ & $0.0 \%$ \\
\%Profile4 & & & & $35.0 \%$ & $35.0 \%$ \\
\%Profile5 & & & & & $6.7 \%$ \\
\hline
\end{tabular}

$n=674$. Note: Bolded values signify best fit.

negatively related to years teaching experience $(r=-0.151$, $p<0.001)$, education level $(r=-0.194, p<0.001)$, and teaching qualification $(r=-0.185, p<0.001)$ of ECEC teacher. Teachers' years teaching experience was positively related to their teaching qualification $(r=0.119, p<0.01)$ and education level $(r=0.135$, $p<0.001)$.

\section{Latent Profile Analysis of Teachers' Play Beliefs}

The first research question in this study examined Chinese ECEC teachers' play beliefs profiles. Latent profile models ranging from 1 to 5 classes were estimated. As shown in Table 4, a twoprofile model was adopted as it had the highest entropy (0.90), and a significant VLMR and BLRT value $(p<0.001)$. Despite having the lowest AIC, BIC, and SSA-BIC value, the four-profile structure's VLMR value was insignificant. In consideration of the model indices and the interpretability of the profiles, a two-profile solution was adopted as the final model in the present study.

As shown in Figure 2, Profile 1 was distinguished by a high level of AGP $(M=4.51, S D=0.04)$ and a low level of FPSSS

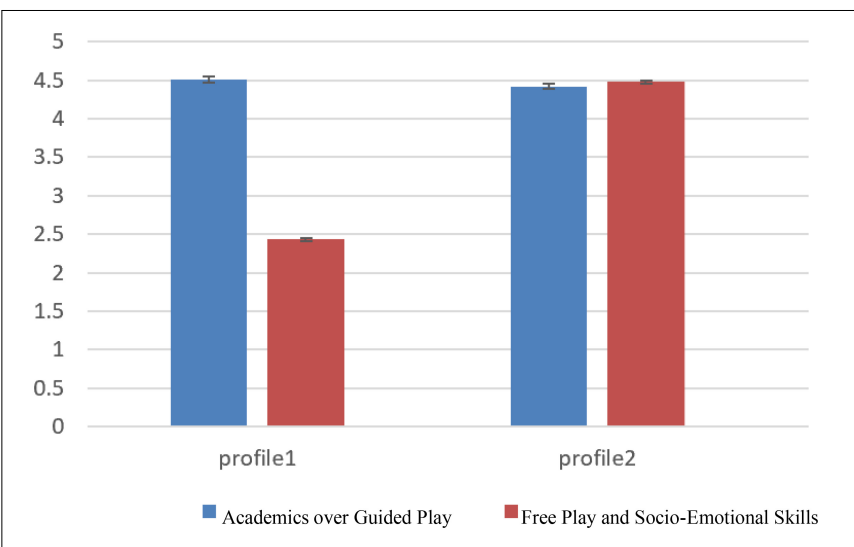

FIGURE 2 | Latent profile analysis results for Teacher's play beliefs.

$(M=2.43, S D=0.02)$. Profile 2 was distinguished by high scores on both $A G P(M=4.42, S D=0.03)$ and FPSSS $(M=4.48$, $S D=0.02)$. The LPA results identified two profiles: (1) High AGP and Low FPSSS (91.1\%), (2) High AGP and FPSSS (9.0\%).

\section{Factors Associated With Teachers' Play Beliefs Profile}

The second research question of this study was to identify whether teachers' years teaching experience, education major, education level, and teaching qualification predicated Chinese ECEC teachers' play beliefs profile. Binary logistic regression was conducted in Mplus using the above indicators to evaluate how these factors related to the likelihood of membership in a Chinese ECEC teachers' play beliefs profile.

As shown in Table 5, comparing the High AGP and Low FPSSS profile (Profile 1) to the High AGP and High FPSSS profile (Profile 2 ), there was a significant difference in years teaching experience. Teachers with 10 years and above of teaching experience were more likely to belong to latent profile 1 (Logits $=1.624, p<0.01$, $\mathrm{OR}=5.257$ ) than those with $0-3$ years of teaching experience. There were no significant differences $(p>0.05)$ in teachers' education major, education level, and teaching qualification comparing Profile 1 to Profile 2.

\section{DISCUSSION}

\section{Constructs and Patterns of Chinese Early Childhood Education and Care Teachers' Play Beliefs}

In collaboration with ECEC teachers and experts in China, this study developed, revised, and validated the Chinese Teachers' Play Beliefs Scale (CTPBS). First, a 27-item pilot version of the measure was culturally adapted by the final author based on the current parental play belief scale (Fogle and Mendez, 2006), then the first author translated it from English into Chinese. A group of Chinese ECEC teachers were asked to comment on the scale's wording and suitability and ECEC experts were consulted with to confirm the scale's content validity. In the process of EFA, 14 
TABLE 5 | Binary logistic regression results of Teacher's play belief profiles.

\begin{tabular}{|c|c|c|c|c|}
\hline \multirow{3}{*}{$\begin{array}{l}\text { Reference group } \\
\text { Profile } 2\end{array}$} & \multicolumn{4}{|l|}{ Comparison group } \\
\hline & \multicolumn{4}{|l|}{ Profile 1} \\
\hline & Predictor & Logits & S.E. & O.R. \\
\hline & \multicolumn{4}{|l|}{ Teaching experience } \\
\hline & $0-3$ years & - & - & - \\
\hline & $4-9$ years & 0.525 & 0.300 & 1.731 \\
\hline & 10 years and above & $1.624^{\star \star}$ & 0.495 & 5.257 \\
\hline & \multicolumn{4}{|l|}{ Major } \\
\hline & Preschool education & - & - & - \\
\hline & Others & 0.035 & 0.484 & 1.036 \\
\hline & \multicolumn{4}{|l|}{ Education } \\
\hline & High school and below & - & - & - \\
\hline & Associated degree & -0.453 & 0.507 & 0.636 \\
\hline & Bachelor degree and above & -0.271 & 0.595 & 0.763 \\
\hline & \multicolumn{4}{|l|}{ Teacher qualification } \\
\hline & No & - & - & - \\
\hline & Yes & 0.056 & 0.336 & 1.058 \\
\hline
\end{tabular}

${ }^{* *} p<0.01, n=674$

items were removed because of unacceptably low communities, their lack of significant loadings on the two factors, or crossloading among factors. The final version of CTPBS was a 13-item scale, which included two constructs: "Academics over Guided Play" (AGP) and "Free Play and Socio-Emotional Skills Support" (FPSSS), which had similar factors of parental play belief scale to Fogle and Mendez (2006) study. However, in line with recent international trends toward intentional teaching in play (Bennett, 2005; Siraj-Blatchford, 2009), the CTPBS further explored not only attitudes on the benefits of child-centered free play, but also adult's participation in child play, and the corresponding focus on skills learned from free and guided play (see Zosh et al., 2018). The items of the CTPBS also seemed to be more generalized than those in the Chinese Parent Play Beliefs Scale (CPPBS; Lin and $\mathrm{Li}, 2018$ ), which was derived from a detailed list of young children's play and preacademic activities. While CTPBS may share some concepts similar to CPPBS-play for fun and play for learning, their differences probably exist because concrete items were appropriate for teachers (as professionals intimately familiar with this nomenclature) but not for parents.

Using a person-centered approach via LPA, the present study revealed a two-profile model: Profile 1, who placed the highest value academic learning (e.g., counting, recognizing letters, reading), a slightly lower value on guided play, and an even lower value on free play and socio-emotional skills (e.g., language, communication, feeling expression, social skills); and Profile 2, who placed a high value both on academic and socio-emotional learning, as well as on guided and free play, albeit to a lesser extent than on the learning. Chinese parents may value adult-guided activities over free play because they believe adult-guided activities are more effective for children's academic learning, which they value more (Rao and Li, 2009; Fung and Cheng, 2012; Sun and Rao, 2017). Interestingly, the item - "It would be more beneficial to read to children than to join in on their play" - which loaded well (0.713) onto the first subscale, AGP, suggested that adult-led instruction such as reading was valued more than even guided play, similar to this value hierarchy shown by many Chinese parents (Fung and Cheng, 2012; Sun and Rao, 2017). Similarly, Q11, "It is more important for children to have good academic skills than to play well with others" suggests a valuing of academics over play that provides a nuance to the valuing of guided play that may be quite culturally specific to Asia, as suggested in the systematic review of Bubikova-Moan et al. (2019). Like profiles of Chinese parental play beliefs where parental involvement moderated children's academic-related play only if those parents valued play for learning, and not if they valued play just for fun (Lin and Li, 2018; Lin et al., 2019), profiles in the current study showed distinct intracultural groups of ECEC teachers who value free play differently. In contrast to the findings of prior studies, the majority of ECEC teachers valued their role in play for children's academic learning above the value of free play for child-initiated learning of socio-emotional skills (Chakravarthi, 2009; Rengel, 2013; Clevenger, 2016; Avornyo and Baker, 2018). Chinese ECEC teachers' valuing of their active role in play contrasts patterns found in western-heritage countries, where teachers are reluctant to "hijack" play's inherent value (e.g., Pyle and Danniels, 2017, p. 274; Colliver, 2019). Similarly, Turkish teachers with the most experience ( $>15$ years) were most likely to be uninvolved in play (Ivrendi, 2017). The majority of Chinese ECEC teachers still appear to value academic learning-and to a lesser extent, guided play-over free play and socio-emotional skills. However, those with less experience, most likely newer teachers, valued guided and free play equally, suggesting they have "caught up" with contemporary trends toward valuing intentional teaching and guided play (Bennett, 2005; Siraj-Blatchford, 2009; Weisberg et al., 2013b), and possibly the contemporary emphasis on valuing and enacting both guided and free play equally (Sylva et al., 2004; Zosh et al., 2018). However, the challenge for Chinese policy is to ensure this valuing of free play and child autonomy is enacted well, as research suggests that it takes years of experience to know how to convert these beliefs to practice (Parker and NeuharthPritchett, 2006; Wen et al., 2011; Yin et al., 2021). While there is much rhetoric regarding the moral imperative to uphold children's human right to play (Colliver and Doel-Mackaway, 2021), it requires skill and expertise to follow children's interests and initiatives in a thoughtful and educational manner (Edwards et al., 2011; Hedges and Cooper, 2016).

In China, the central status of play as the principal activity in kindergarten was enshrined in the 2001 Guidelines for Kindergarten Education Practice (The Ministry of Education of the People's Republic of China, 2001). With educators responding positively to the policies, great changes have taken place in kindergartens across China. Anji play, a successful experiment in child-initiated outdoor play at preschool, is being expanded across the country and learned by ECEC educators throughout the world (Wang, 2018). The current results are consistent with the idea that the benefits of a childcentered, play-based curriculum have more recently become widely accepted by Chinese ECEC teachers. Thus, Profile 2 in this study unsurprisingly valued guided and free play equally. 
Many preschool educators, however, may be influenced to the expectations of the families that they serve to nurture early learners and prepare young children for later academic learning (Fung and Cheng, 2012; Sun and Rao, 2017), and this tendency appears to be reflected particularly in Profile 1, high in AGP, academic learning over guided play support, and low in FPSSS. Moreover, since the importation of notions and practices imported from European-heritage countries, there has exited a conflict and tension between "host" traditional values and "guest" ones, where adults adopt different patterns of acculturation and adjustment of their culturally based beliefs about play (Berry, 1997; Rao et al., 2010). Confucian heritage culture appears to deeply rooted in China, with some teachers still tending to view recreation as akin to laziness, and playing as not being useful, with high expectations of children's academic achievement (Lee, 1996; Li, 2003; Rao and Chan, 2009). If the 1:1 ratio of adult- and child-initiated activities, and 1:1 ratio of adult- and child-guided play (Sylva et al., 2004), is also optimal in the Chinese context, these background influences remain a significant challenge in the enterprise of improving Chinese ECEC provision: for more experienced teachers because they hold views less consistent with contemporary research evidence, and for less experienced teachers because they are more likely to hold less managerial and therefore influential roles.

\section{Teachers' Backgrounds Associated With Play Belief Patterns}

Studies have suggested that teachers' educational background and teaching experience are related to teaching beliefs (Spodek, 1988; Charlesworth et al., 1993; Calderhead, 1996). The current study found that years of teaching experience predicted the profiles of ECEC teachers' play beliefs. However, in contrast with those with less teaching experience, teachers with a decade or more teaching experience were less likely to have a free play and socio-emotional skill focus. There were no significant differences in teachers' education major, education level, and teaching qualification comparing Profile 1 to Profile 2.

These findings contrast those of previous studies, which have suggested that more experienced Chinese teachers have more positive views on the protection of children's right to play and an endorsement of child-centered free play (Liu, 2014). Since child play is regarded as the principal activity in ECEC, how to better support and guide child play has become the fundamental component and focus of teacher training and professional learning. On the other hand, previous studies (e.g., Wu et al., 2018) have generally shown Chinese ECEC teachers have valued play less than those from Western-heritage countries (as highlighted by Q6 and Q12 of the AGP), with the growing influence of western ideas, it seems likely that more recently trained teachers would espouse values more supportive of free play and holistic learning. It is possible that the current study is showing newer teachers have had more contemporary training reflecting an equal emphasis on guided and free play, and holistic learning as per the balancing of academic and socioemotional learning. It is notable that previous research has shown that more teaching experience can be a predictor of higher teacher self-efficacy, which is related to the autonomy of teachers' professional development (Cheung, 2008; von Suchodoletz et al., 2018) as well as their likelihood of enacting a play-based curriculum, which may involve minimal adult intervention in play (Yin et al., 2021). On the other hand, Chinese teachers with less teaching experience may be more likely to enact the recent ECEC education reforms emphasizing play-based, individualized and active learning (Liu and Feng, 2005). However, implementing these values in practice may require experience these teachers do not yet possess (Parker and Neuharth-Pritchett, 2006; Yin et al., 2021), or specialist in-service training (Wen et al., 2011; Hedges and Cooper, 2016; Colliver, 2019).

The changing values of Chinese ECEC teachers suggested by the current data are likely reflective of the rising influences of the Zone of Proximal Development (Vygotsky, 1978) and Reggio Emilia (Edwards et al., 2011) and Project (Helm and Katz, 2011) approaches in China in the late twentieth and early twenty-first centuries (Qi and Melhuish, 2017), the relative value of free play was significantly lower for the group who received teacher training more than 10 years ago (although such approaches can be effectively used to balance child- and teacher-oriented activities; Veraksa et al., 2021). A review of the prominent ECEC literature published in Mandarin over the past two decades reflects a redirection of value orientation in ECEC teachers' beliefs about free play and learning socio-emotional skills. Affected by Western ECEC concepts and the Developmentally Appropriate Practice (DAP) approach (McMullen et al., 2005), Chinese literature in the early twenty-first century paid more attention to the value of child-centered play, children's autonomy and holistic learning, including an emphasis on social and emotional skills (e.g., Qiu, 2001; Jing and Chen, 2002). However, partly due to parental expectations (e.g., Sun and Rao, 2017) and some empirical evidence (e.g., Hu et al., 2017), there has been a recent redirection in the play literature toward striking a balance between child-initiated and teacher-led play, with more emphasis on teachers' active role in supporting and guiding play for learning (e.g., Lin et al., 2019; Deng, 2021). It is possible that this change of values, and potentially from their influence on teacher education, is reflected in the significant belief differences found here between teachers with more or less experience.

\section{Limitations and Future Research Directions}

Several limitations need to be noted when interpreting the current findings and addressed in future studies. First, the sample was limited to teachers in Fuzhou, a highly developed city in China. There is a need for future studies to involve ECEC teachers from less-developed areas of China, to examine play beliefs more comprehensively in contemporary China. Second, some researchers have argued that the improvement of the statistical ability of LPA would be brought from more class indicators and a larger sample size (Nylund et al., 2007). Therefore, it is desirable that further studies would be conducted with larger samples using more class indicators. Third, the data about play beliefs were reported by ECEC teachers, which may lead to self-report bias or 
socially desirable response sets. In further research, apart from teachers' self-reports, researchers might consider using otherinformant ratings or observation. Fourth, previous studies have investigated parental and teachers' play beliefs, but few have examined whether ECEC administrators and teachers differ in how they view child play, which is needed to be explored in future studies. Fourth, although the Parent Play Belief Scale was here adapted to reflect contemporary international trends toward balancing guided and free play (Bennett, 2005; Siraj-Blatchford, 2009), many of the items did not meet communality criteria outlined in the section "Materials and Methods". This resulted in a smaller scale than would be anticipated if using factors derived from the original scale (Fogle and Mendez, 2006). Finally, our study did not explore and verify the cause-effect relationship between teachers' play beliefs and child outcomes, which calls for further studies considering these variables (e.g., Lin and Li, 2018).

\section{CONCLUSION}

This study suggested that Chinese ECEC teachers with more teaching experience value free play and socio-emotional learning less than their less experienced counterparts. A key contribution of this research is that it offers a data-driven typology of Chinese ECEC teacher groups based on their unique configuration of play beliefs, confirming patterns elucidated in prior, predominantly qualitative research (Rao and Li, 2009; Bubikova-Moan et al., 2019) and quantifying them. Moreover, using person-centered methodology via LPA grounded in a cultural-historical framework, this study explored the profiles of Chinese teachers' play beliefs and the associations with their backgrounds, which extended prior studies that have typically relied on variable-centered approaches to examine ECEC teachers' play beliefs. The results of this study, although preliminary, have implications for teacher training, theory and policy. The extant literature suggests that there exist tensions not only between Chinese traditional and practices and Western-heritage beliefs but also between the play-based values orientation of educators and academic-skills focus of parents in contemporary China (Sun and Rao, 2017). Limited empirical research, however, has explored the play beliefs of ECEC teachers within the context of the internal and external tensions and changes in the value of play in China. This study has begun to contribute to knowledge about the status of play in Chinese ECEC, indicating not just the valuing guided over free play and academic over socio-emotional skills, but also the variability within a minority ( 9\%) of Chinese ECEC teachers' attitudes showing greater valuing of socio-emotional learning via free play. If a balance of guided and free play is optimal in the Chinese context, as it has shown to be in Western contexts

\section{REFERENCES}

Avornyo, E. A., and Baker, S. (2018). The role of play in children's learning: the perspective of Ghanaian early years stakeholders. Early Years 41, 174-189. doi: 10.1080/09575146.2018.147 3344 (e.g., Sylva et al., 2004), the current relationship between the two patterns of play beliefs and their teaching experience suggests that in-service training resources could be focused on helping older teachers to balance the academic-oriented and child-centered play activities at preschool, especially how that might be achieved using free play that allows child-led learning and autonomy. At the policy level, the existing profiles of Chinese teachers suggest that educational authorities and kindergarten principals in China might seek to train more experienced teachers in the ideal balance between guided and free play (Sylva et al., 2004; Siraj-Blatchford, 2009), and less experienced teachers in how to implement free play in the presumably more nuanced ways seen by in the practice of their more experienced counterparts (Parker and NeuharthPritchett, 2006; Wen et al., 2011). The current findings, therefore, imply that there remains some work for Chinese ECEC practice and policy to meet the recommendations implicit in the evidence base on balancing guided and free play and the international push for intentional ECEC teachers who value and implement adultand child-initiated activities equally.

\section{DATA AVAILABILITY STATEMENT}

The raw data supporting the conclusions of this article will be made available by the authors, without undue reservation.

\section{ETHICS STATEMENT}

Ethical review and approval was not required for the study on human participants in accordance with the local legislation and institutional requirements. The patients/participants provided their written informed consent to participate in this study.

\section{AUTHOR CONTRIBUTIONS}

XL co-designed the survey instrument, conducted the statistical analyses, and drafted the manuscript. YL and MX assisted with data collection, extraction and analysis, and also drafted the introduction and literature review. YC determined the research questions and focus, co-designed the survey instrument, and edited the manuscript. All authors contributed to the article and approved the submitted version.

\section{FUNDING}

This project was supported by the Fujian Province General Program of Social Science in 2020 (FJ2020B056).

Bámaca-Colbert, M. Y., and Gayles, J. G. (2010). Variable-centered and personcentered approaches to studying Mexican-origin mother-daughter cultural orientation dissonance. J. Youth Adolesc. 39, 1274-1292.

Baustad, A. G., Rønning, W., and Bjørnestad, E. (2018). Norwegian ECEC staff's thinking on quality of interaction. Early Child Dev. Care 190, 1969-1982. doi: $10.1080 / 03004430.2018 .1553874$ 
Beaton, D. E., Bombardier, C., Guillemin, F., and Ferraz, M. B. (2000). Guidelines for the process of cross-cultural adaptation of self-report measures. Spine 25, 3186-3191.

Bennett, J. (2005). Curriculum issues in national policy-making. Eur. Early Child. Educ. Res. J. 13, 5-23. doi: 10.1080/13502930585209641

Berry, W. (1997). Immigration, acculturation, and adaptation. Appl. Psychol. Int. Rev. 46, 5-68. doi: 10.1111/j.1464-0597.1997.tb01087.x

Breathnach, H., Danby, S., and O'Gorman, L. (2017). 'Are you working or playing?' Investigating young children's perspectives of classroom activities. Int. J. Early Years Educ. 25, 439-454. doi: 10.1080/09669760.2017.1316241

Bronfenbrenner, U., and Morris, P. A. (2006). "The bioecological model of human development," in Handbook of Child Psychology: Theoretical Models of Human Development, 6th Edn. eds W. Damon and R. M. Lerner (New York, NY: John Wiley \& Sons), 793-828.

Bubikova-Moan, J., Næss Hjetland, H., and Wollscheid, S. (2019). ECE teachers' views on play-based learning: a systematic review. Eur. Early Child. Educ. Res. J. 27, 776-800. doi: 10.1080/1350293X.2019.1678717

Calderhead, J. (1996). "Teachers: beliefs and knowledge," in Handbook of Educational Psychology, eds D. C. Berliner and R. C. Calfee (New York, NY: Macmillan Library Reference), 703-725.

Chaiklin, S. (2012). "A conceptual perspective for investigation motive in culturalhistorical theory," in Motives in Children's Development: Cultural-Historical Approaches, eds M. Hedegaard, A. Edwards, and M. Fleer (Maidenhead: Cambridge University Press), 209-224. doi: 10.1017/cbo9781139049474.016

Chakravarthi, S. (2009). Preschool Teachers' Beliefs and Practices of Outdoor Play and Outdoor Environments, Dissertations \& Theses, - Gradworks. Available online at: http://libres.uncg.edu/ir/listing.aspx?id=2474 (accessed November 5, 2021).

Charlesworth, R., Hart, C. H., Burts, D. C., Thomasson, R. H., Mosley, J., and Fleege, P. O. (1993). Measuring the developmental appropriateness of kindergarten teachers' beliefs and practices. Early Childhood Res. Q. 8, 255-276. doi: 10.1016/S0885-2006(05)80067-5

Cheung, H. Y. (2008). Teacher efficacy: a comparative study of Hong Kong and Shanghai primary in-service teachers. Aust. Educ. Res. 35, 101-123. doi: 10. 1007/BF03216877

Clark, C. M., and Peterson, P. L. (1986). “Teachers' thought processes," in Handbook of Research on Teaching, ed. M. C. Wittrock (New York, NY: Macmillan), 255-296.

Cleland, C. M., Rothschild, L., and Haslam, N. (2000). Detecting latent taxa: Monte Carlo comparison of taxometric, mixture model, and clustering procedures. Psychol. Rep. 87, 37-47. doi: 10.2466/pr0.2000.87.1.37

Clevenger, M. T. (2016). Preservice Teachers' Beliefs About Play in Kindergarten. (Doctoral Dissertation). Available online at: https://scholarcommons.sc.edu/ etd/3603 (accessed November 5, 2021).

Colliver, Y. (2019). Intentional or incidental? Learning through play according to Australian educators' perspectives. Early Years 1-18. doi: 10.1080/09575146. 2019.1661976

Colliver, Y., and Doel-Mackaway, H. (2021). Article 31, 31 years on: choice and autonomy as a framework for implementing children's right to play in early childhood services. Hum. Rights Law Rev. 21, 566-587. doi: 10.1093/hrlr/ ngab011

Deng, X. (2021). 幼儿自发性游戏行为的价值与支持策略 (The value and strategies for guiding children's play behavior). Stud. Presch. Educ. 3, 89-92. doi: 10.26549/ jxffcxysj.v3i13.5805

Edwards, C., Gandini, L., and Forman, G. (2011). The Hundred Languages of Children: The Reggio Emilia Experience in Transformation, 3rd Edn. Elmwood Park, NJ: Praeger.

Enz, B., and Christie, J. F. (1993). Teacher play interaction styles and their impact on children's oral language and literacy play. Int. J. Early Child. Spl. Educ. 2, 55-75.

Fisher, K. R., Hirsh-Pasek, K., Newcombe, N., and Golinkoff, R. M. (2013). Taking shape: supporting preschoolers' acquisition of geometric knowledge through guided play. Child Dev. 84, 1872-1878. doi: 10.1111/cdev.12091

Fives, H., and Buehl, M. M. (2012). "Spring cleaning for the "messy" construct of teachers' beliefs: what are they? Which have been examined? What can they tell us?" in APA Educational Psychology Handbook: Individual Differences and Cultural and Contextual Factors, eds K. R. Harris, S. Graham, T.
Urdan, S. Graham, J. M. Royer, and M. Zeidner (Washington, DC: American Psychological Association), 471-499. doi: 10.1037/13274-019

Fleer, M. (2008). "Interpreting research protocols - the child's perspective," in Studying Children: A cultural-Historical Approach, eds M. Hedegaard and M. Fleer (Maidenhead: Open University Press), 88-103.

Fleer, M. (2010). Early Learning and Development: Cultural-Historical Concepts in Play. New York, NY: Cambridge University Press.

Fogle, L. M., and Mendez, J. L. (2006). Assessing the play beliefs of African American mothers with preschool children. Early Child. Res. Q. 21, 507-518. doi: 10.1016/j.ecresq.2006.08.002

Foti, R. J., Bray, B. C., Thompson, N. J., and Allgood, S. F. (2012). Know thy self, know thy leader: contributions of a pattern-oriented approach to examining leader perceptions. Leadersh. Q. 23, 702-717. doi: 10.1016/j.leaqua.2012.03.00

Fung, C. K. H., and Cheng, D. P. W. (2012). Consensus or dissensus? Early Years 32, 17-33. doi: 10.1080/09575146.2011.599794

Gupta, A. (2011). "Play and pedagogy framed within India’s historical, sociocultural and pedagogical context," in Rethinking Play and Pedagogy in Early Childhood Education: Concepts, Contexts and Cultures, ed. S. Rogers (Abingdon-on-Thames: Routledge), 86-99. doi: 10.4324/9780429454042-7

Haight, W. L., Parke, R. D., and Black, J. E. (1997). Mothers' and fathers' beliefs about and spontaneous participation in their toddler's pretend play. Merrill Palmer Q. 43, 271-290.

Hedegaard, M. (2008). "Principles for interpreting research protocols," in Children: A Cultural-Historical Approach, eds M. Hedegaard, M. Fleer (Maidenhead: Open University Press), 46-64.

Hedegaard, M. (2009). Children's development from a cultural-historical approach: children's activity in everyday local settings as foundation for their development. Mind Cult. Act. 16, 64-82. doi: 10.1080/107490308024 7737

Hedges, H., and Cooper, M. (2016). Inquiring minds: theorizing children's interests. J. Curric. Stud. 48, 303-322. doi: 10.1080/00220272.2015.1109711

Helm, J., and Katz, L. (2011). Young Investigators: The Project Approach in the Early Years, 2nd Edn. New York, NY: Teachers College, Columbia University.

Howard, M. C., and Hoffman, M. E. (2018). Variable-centered, person-centered, and person-specific approaches: where theory meets the method. Organ. Res. Methods 21, 846-876. doi: 10.1177/1094428117744021

Hu, B. Y., Fan, X., Wu, Z., LoCasale-Crouch, J., Yang, N., and Zhang, J. (2017). Teacher-child interactions and children's cognitive and social skills in Chinese preschool classrooms. Child. Youth Serv. Rev. 79, 78-86. doi: 10.1016/ j.childyouth.2017.05.028

Hyvonen, P. (2011). Play in the school context? The perspectives of finnish teachers. Aust J. Teach. Educ. 36, 65-83. doi: 10.14221/ajte.2011v36n8.5

Isaacs, S. (1929). The Nursery Years. London: Routledge and Keagan Paul.

Ivrendi, A. (2017). Early childhood teachers' roles in free play. Early Years 40, 273-286. doi: 10.1080/09575146.2017.1403416

Izumi-Taylor, S., Ingrid, P., and Cosby, S. (2010). Perspectives of play in three nations: a comparative study in Japan, the United States, and Sweden. Early Child. Res. Pract. 12, 1-12.

Jiang, S., and Han, M. (2016). Parental beliefs on children's play: comparison among mainland Chinese, Chinese immigrants in the USA, and EuropeanAmericans. Early Child Dev. Care 186, 341-352. doi: 10.1080/03004430.2015. 1030633

Jing, W., and Chen, H. (2002). 关于游戏与儿童发展的思考 (Thoughts on free play and children's development) [X. Lin, Trans.]. Stud. Presch. Educ. 4, 36-38.

Johnson, J. E., Christie, J. F., and Yawkey, T. D. (1999). Play and Early Childhood Development, 2nd Edn. New York, NY: Longman.

Kansanen, P. (1991). Pedagogical thinking: the basic problem of teacher education. Eur. J. Educ. 26, 251-260. doi: 10.2307/1503027

Lee, W. O. (1996). "The cultural context for Chinese learners: conceptions of learning in the confusion tradition," in The Chinese Learner: Cultural, Psychological and Contextual Influences, eds D. A. Watkins and J. B. Biggs (Hong Kong/Melbourne: Comparative Education Research Centre, The University of Hong Kong/Australia Council for Educational Research), 25-41.

Li, H., and Wang, X. C. (2017). "International perspectives on early childhood education in the mainland China, Hong Kong, Macao and Taiwan," in Early Childhood Education in Chinese Societies, eds N. Rao, J. Zhou, and J. Sun (New York, NY: Springer), 235-250. 
Li, H., and Chen, J. J. (2017). Evolution of the early childhood curriculum in China: the impact of social and cultural factors on revolution and innovation. Early Child Dev. Care 187, 1471-1483. doi: 10.1080/03004430.2016.1220373

Li, J. (2003). The core of confucian learning. Am. Psychol. 58, 146-147. doi: 10. 1037/0003-066X.58.2.146

Li, J. (2012). Cultural Foundations of Learning: East and West. New York, NY: Cambridge University Press.

Lin, X., and Li, H. (2018). Parents' play beliefs and engagement in young children's play at home. Eur. Early Child. Educ. Res. J. 26, 161-176. doi: 10.1080/1350293X. 2018.1441979

Lin, X., Li, H., and Yang, W. (2019). Bridging a cultural divide between play and learning: parental Ethnotheories of young children's play in modern China. Early Educ. Dev. 30, 82-97. doi: 10.1080/10409289.2018.1 514846

Lin, X., Li, H., and Yang, W. (2020). You reap what you sow: profiles of Chinese fathers' play beliefs and their relation to young children's developmental outcomes. Early Educ. Dev. 31, 426-441. doi: 10.1080/10409289.2019.1652444

Liu, Y., and Feng, X. (2005). Kindergarten educational reform during the past two decades in mainland China: achievements and problems. Int. J. Early Years Educ. 13, 93-99. doi: 10.1080/09669760500170933

Liu, Z. (2014). Research on Children Play Rights, Doctoral Thesis [in Chinese]. Nanjing: Nanjing Normal University.

Matusov, E. (2007). In search of 'the appropriate' unit of analysis for sociocultural research. Cult. Psychol. 13, 307-333. doi: 10.1177/1354067x07079887

McCoy, D. C., Yoshikawa, H., Ziol-Guest, K. M., Duncan, G. J., Schindler, H. S., Magnuson, K., et al. (2017). Impacts of early childhood education on mediumand long-term educational outcomes. Educ. Res. 46, 474-487. doi: 10.3102/ 0013189X17737739

McMullen, M., Elicker, J., Wang, J., Erdiller, Z., Lee, S. M., Lin, C. H., et al. (2005). Comparing beliefs about appropriate practice among early childhood education and care professionals from the U.S., China, Taiwan, Korea and Turkey. Early Child. Res. Q. 20, 451-464. doi: 10.1016/j.ecresq.2005.10.005

Mooi, E., and Sarstedt, M. (2011). A Concise Guide to Market Research: The Process, Data, and Methods Using IBM SPSS Statistics. Berlin: Springer-Verlag.

Morin, A. J., Morizot, J., Boudrias, J. S., and Madore, I. (2011). A multi-foci person-centered perspective on workplace affective commitment: a latent profile/factor mixture analysis. Organ. Res. Methods 14, 58-90. doi: 10.1177/ 1094428109356476

Muthén, L. K., and Muthén, B. O. (1998-2010). Mplus User's Guide. Los Angeles, CA: Muthén \& Muthén.

Nilsen, T. R. (2021). Pedagogical intentions or practical considerations when facilitating children's play? Teachers' beliefs about the availability of play materials in the indoor ECEC environment. Int. J. Child Care Educ. Policy 15, doi: 10.1186/s40723-020-00078-y

Nylund, K. L., Asparouhov, T., and Muthén, B. O. (2007). Deciding on the number of classes in latent class analysis and growth mixture modeling: a Monte Carlo simulation study. Struct. Equ. Modeling14, 535-569. doi: 10.1080/ 10705510701575396

Organization for Economic Cooperation and Development [OECD] (2017). Starting Strong 2017 - Key OECD Indicators on Early Childhood Education and Care. Paris: OECD Publishing.

Pajares, M. F. (1992). Teachers' beliefs and educational research: cleaning up a messy construct. Rev. Educ. Res. 62, 307-332. doi: 10.2307/1170741

Parker, A., and Neuharth-Pritchett, S. (2006). Developmentally appropriate practice in kindergarten: factors shaping teacher beliefs and practice. J. Res. Child. Educ. 21, 65-78. doi: 10.1080/02568540609594579

Peterson, S. S., Madsen, A., San Miguel, J., and Jang, S. Y. (2018). Children's rough and tumble play: perspectives of teachers in northern Canadian indigenous communities. Early Years 38, 53-67. doi: 10.1080/09575146.2016.12 19844

Pyle, A., and Danniels, E. (2017). A continuum of play-based learning: the role of the teacher in play-based pedagogy and the fear of hijacking play. Early Educ. Dev. 28, 274-289. doi: 10.1080/10409289.2016.1220771

Pyle, A., Pyle, M. A., Prioletta, J., and Alaca, B. (2021). Portrayals of play-based learning. Am. J. Play 13, 53-86.

Qi, X., and Melhuish, E. C. (2017). Early childhood education and care in China: history, current trends and challenges. Early Years 37, 268-284. doi: 10.1080/ 09575146.2016 .1236780
Qiu, X. (2001). 关于儿童的自主性游戏 (Thoughts on children's spontaneous play). [X. Li, Trans.]. Stud. Presch. Educ. 6, 36-37.

Rao, N., and Chan, C. K. K. (2009). "Moving beyond paradoxes: understanding Chinese learners and their teachers," in Revisiting the Chinese Learner: Changing Contexts, Changing Education, eds C. K. K. Chan and N. Rao (Hong Kong: The University of Hong Kong: Comparative Education Research Centre/Springer Academic Publishers.), 3-31. doi: 10.1007/978-90-481-3840-1_1

Rao, N., and Li, H. (2009). "Eduplay": beliefs and practices related to play and learning in Chinese kindergartens," in Play and Learning in Early Childhood Settings: International Perspectives, eds I. Pramling-Samuelsson and M. Fleer (New York, NY: Springer Netherlands), 97-116. doi: 10.1111/bjep.12086

Rao, N., Ng, S. S., and Pearson, E. (2010). "Preschool pedagogy: a fusion of traditional Chinese beliefs and contemporary notions of appropriate practice," in Revisiting the Chinese Learner, eds K. K. Chan and N. Rao (Hong Kong: Springer), 255-279.

Rengel, K. (2013). Preschool teachers' attitudes toward play. Croat. J. Educ. 16, 113-125.

Rogers, S. (2013). "The pedagogization of play in early childhood education: a Bernsteinian perspective," in Varied Perspectives on Play and Learning, eds O. F. Lillemyr, S. Dockett, and B. Perry (Charlotte, NC: Information Age Publishing), 159-174.

Rogoff, B. (1995). "Observing sociocultural activity on three planes: participatory appropriation, guided participation, and apprenticeship," in Sociocultural Studies of Mind, eds J. V. Wertsch, P. del Rio, and A. Alvarez (Cambridge: Cambridge University Press), 139-164. doi: $10.1017 /$ cbo 9781139174299.008

Rogoff, B. (2003). The Cultural Nature of Human Development. Oxford: Oxford University Press.

Sandberg, A., and Samuelsson, I. P. (2003). Preschool teachers' play experiences then and now. Early Child. Res. Pract. 5, 1-17. doi: 10.1016/j.jcfm.2006.08.009

Siraj-Blatchford, I. (2009). Conceptualising progression in the pedagogy of play and sustained shared thinking in early childhood education: a Vygotskian perspective. Educ. Child Psychol. 26, 77-89.

Smilansky, S., and Shefatya, L. (1990). Facilitating Play: A Medium for Promoting Cognitive, Socio-Emotional and Academic Development in Young Children. Gaithersburg, MD: Psychosocial and Educational Publications.

Spodek, B. (1988). "Implicit theories of early childhood teachers: foundations for professional behavior," in Professionalism and the Early Childhood Practitioner, eds B. Spodek, O. N. Saracho, and D. L. Peters (New York, NY: Teachers College Press), 161-172.

Sun, J., and Rao, N. (2017). "Growing up in Chinese families and societies," in Early Childhood Education in Chinese Societies, eds N. Rao, J. Zhou, and J. Sun (Dordrecht: Springer), 199-200.

Sylva, K., Melhuish, E., Sammons, P., Siraj-Blatchford, I., and Taggart, B. (2004). The Effective Provision of Pre-School Education (EPPE) Project: Final Report. I. o. Education. London: Great Britain. Department for Education and Skills.

The Ministry of Education of the People's Republic of China (MOE) (2001). Guidelines for Kindergarten Education Practice. Beijing: The Ministry of Education of the People's Republic of China.

Thompson, C. W., Aspinall, P., and Montarzino, A. (2008). The childhood factor: adult visits to green places and the significance of childhood experience. Environ. Behav. 40, 111-143. doi: 10.1177/0013916507300119

Tobin, J., Hsueh, Y., and Karasawa, M. (2009). Preschool in Three Cultures Revisited: China, Japan, and the United States. Chicago, IL: University of Chicago Press.

Ulferts, H., Wolf, K. M., and Anders, Y. (2019). Impact of process quality in early childhood education and care on academic outcomes: longitudinal metaanalysis. Child Dev. 90, 1474-1489. doi: 10.1111/cdev.13296

van der Aalsvoort, G., Prakke, B., Howard, J., König, A., and Parkkinen, T. (2015). Trainee teachers' perspectives on play characteristics and their role in children's play: an international comparative study amongst trainees in the Netherlands, Wales, Germany and Finland. Eur. Early Child. Educ. Res. J. 23, 277-292. doi: 10.1080/1350293X.2015.1016807

van Hoorn, J., Nourot, P. M., Scales, B., and Alward, K. R. (2014). Play at the Center of the Curriculum. London: Pearson Higher Ed.

Veraksa, N., Sheridan, S., and Colliver, Y. (2021). Balancing child-centred with teacher-directed approaches to early education: incorporating young children's perspectives. Pedagogy Cult. Soc. doi: 10.1080/14681366.2021.1955736 
Vermunt, J. K. (2010). Latent class modeling with covariates: two improved three-step approaches. Polit. Anal. 18, 450-469. doi: 10.1093/pan/mpq025

Vermunt, J. K., and Magidson, J. (2002). "Latent class cluster analysis," in Applied Latent Class Analysis, eds J. A. Hagenaars and A. L. McCutcheon (Cambridge: Cambridge University Press), 89-106. doi: 10.1017/cbo9780511499531.004

von Suchodoletz, A., Jamil, F. M., Larsen, R. A., and Hamre, B. K. (2018). Personal and contextual factors associated with growth in preschool teachers' self-efficacy beliefs during a longitudinal professional development study. Teach. Teach. Educ. 75, 278-289. doi: 10.1016/j.tate.2018.07.009

Vygotsky, L. S. (1978). Mind in Society: The Development of Higher Psychological Processes. Cambridge, MA: Harvard University Press.

Vygotsky, L. S. (2004). "The problem and method of investigation," in The essential Vygotsky, eds R. W. Rieber and D. K. Robinson (New York, NY: Plenum), 33-42. doi: 10.1007/978-0-387-30600-1_2

Wang, Z. (2018). The encurriculuming of play. Presch. Educ. 12, 3-8.

Watson, D., Clark, L. A., and Tellegen, A. (1988). Development and validation of brief measures of positive and negative affect: the PANAS scales. J. Pers. Soc. Psychol. 54, 1063-1070. doi: 10.1037/0022-3514.54.6.1063

Weisberg, D. S., Hirsh-Pasek, K., and Golinkoff, R. M. (2013a). Embracing complexity: rethinking the relation between play and learning: comment on Lillard et al. (2013). Psychol. Bull. 139, 35-39. doi: 10.1037/a0030077

Weisberg, D. S., Hirsh-Pasek, K., and Golinkoff, R. M. (2013b). Guided play: where curricular goals meet a playful pedagogy. Mind Brain Educ. 7, 104-112. doi: $10.1111 / \mathrm{mbe} .12015$

Wen, X., Elicker, J. G., and McMullen, M. B. (2011). Early childhood teachers'. Early Educ. Dev. 22, 945-969. doi: 10.1080/10409289.2010.507495

Wu, S. C., Faas, S., and Geiger, S. (2018). Chinese and German teachers' and parents' conceptions of learning at play - similarities, differences, and (in)consistencies. Eur. Early Child. Educ. Res. J. 26, 229-245. doi: 10.1080/ 1350293X.2018.1442034

Wu, S. C., and Rao, N. (2011). Chinese and German teachers' conceptions of play and learning and children's play behaviour. Eur. Early Child. Educ. Res. J. 19, 469-481. doi: 10.1080/1350293X.2011.623511
Yang, W., and Li, H. (2018). A school-based fusion of East and West: a case study of modern curriculum innovations in a Chinese kindergarten. J. Curriculum Stud. 50, 17-37. doi: 10.1080/00220272.2017.1294710

Yin, H., Keung, C. P. C., and Tam, W. W. Y. (2021). What facilitates kindergarten teachers' intentions to implement play-based learning? Early Child. Educ. J. doi: 10.1007/s10643-021-01176-3

Zhu, J., and Zhang, J. (2008). Contemporary trends and developments in early childhood education in China. Early Years 28, 173-182. doi: 10.1080/ 09575140802163584

Zhu, J., and Zhang, J. (2018). "Review and reflection on the curriculum reform of early childhood education in China," in International Handbook of Early Childhood Education, eds M. Fleer and B. Van Oers (Dordrecht: Springer), 1173-1189. doi: 10.1007/978-94-024-0927-7_60

Zosh, J. M., Hirsh-Pasek, K., Hopkins, E. J., Jensen, H., Liu, C., Neale, D., et al. (2018). Accessing the inaccessible: redefining play as a spectrum [Review]. Front. Psychol. 9:1124. doi: 10.3389/fpsyg.2018.01124

Conflict of Interest: The authors declare that the research was conducted in the absence of any commercial or financial relationships that could be construed as a potential conflict of interest.

Publisher's Note: All claims expressed in this article are solely those of the authors and do not necessarily represent those of their affiliated organizations, or those of the publisher, the editors and the reviewers. Any product that may be evaluated in this article, or claim that may be made by its manufacturer, is not guaranteed or endorsed by the publisher.

Copyright (c) 2021 Lin, Liao, Xue and Colliver. This is an open-access article distributed under the terms of the Creative Commons Attribution License (CC BY). The use, distribution or reproduction in other forums is permitted, provided the original author(s) and the copyright owner(s) are credited and that the original publication in this journal is cited, in accordance with accepted academic practice. No use, distribution or reproduction is permitted which does not comply with these terms. 